\title{
MODEL PENGELOLAAN BENDUNG KARET UNTUK PERTANIAN DAN PENANGGULANGAN BANJIR DI PANTAI UTARA JAWA
}

\author{
Fatchur Roehman, ST. MT \\ Fakultas Teknik Universitas Sultan Fatah (UNISFAT) Demak \\ fatchurroehman@gmail.com \\ Jl. Raya Katonsari 19 Demak Telpon (0291) 686227
}

\begin{abstract}
Abstrak, Wilayah pantai utara banyak terdapat sumberdaya air, baik yang berupa air tanah, sungai, maupun laut. Tentu saja tidak mudah untuk mengolah sumberdayasumberdaya tersebut, banyak permasalahan yang harus diselesaikan dalam mengolah sumberdaya tersebut, misalnya masalah banjir dan rob di pantai utara Jawa Tengah, kekeringan saat kemarau melanda, bagaimana kita harus menyediakan air baku dan air untuk irigasi ketika kekeringan melanda, dan permasalahan lainnya. Salah satu solusi yang tepat adalah dengan membuat bendung karet.

Perumusan masalah dengan model bendung karet isi air yang tepat harus diikuti dengan sistem stabilitas bendung dalam menahan aliran. Oleh karena itu masalah utama yang akan dikaji dalam penelitian ini adalah model bendung karet isi air dalam sistem pengelolaan yang lebih mudah, kajian terhadap efektivitas hidrolik model bendung karet isi air,

Maksud dan tujuan penelitian adalah menganalisa efektivitas hidrolik bendung karet dalam stabiltas menahan beban aliran, menganalisis karakteristik bendung karet sehingga didapatkan material bendung yang baik berdasarkan teknologi tepat guna, melakukan analisis stabilitas terhadap aliran yang terjadi pada model bendung karet isi air, simulasi prototipe bendung karet isi air.
\end{abstract}

Kata kunci : Bendung Karet, Model Pengelolaan, Penanggulangan Banjir.

\section{PENDAHULUAN \\ Latar Belakang}

Pantai utara banyak terdapat sumberdaya air, baik yang berupa air tanah, sungai, maupun laut, tentu saja tidak mudah untuk mengolah sumberdaya tersebut, banyak permasalahan yang harus diselesaikan dalam mengolah sumberdaya tersebut, misalnya masalah banjir dan rob di Pantai utara Jawa Tengah, kekeringan saat kemarau melanda, bagaimana kita harus menyediakan air baku dan air untuk irigasi ketika kekeringan melanda, dan permasalahan lainnya. Salah satu solusi yang tepat adalah dengan membuat bendung karet yang berisikan air, biasanya berisikan angin namun dengan ini saya mencoba memakai bendung karet yang berisi air agar lebih mudah dan efisien perawatannya.

Maksud dan Tujuan Analisis efektivitas hidrolik bendung karet isi air. Menganalisis karakteristik bendung karet isi air sehingga didapatkan material bendung yang baik berdasarkan teknologi tepat guna. Melakukan analisis stabilitas terhadap aliran yang terjadi pada model bendung karet isi air. Simulasi prototipe bendung karet isi air.

KAJIAN PUSTAKA 
Bendung (Weir) adalah Konstruksi Bangunan Air yang melintang sungai yang bertujuan untuk menaikkan muka air sungai di Upstream. Tujuan selebihnya adalah dengan naiknya muka air sehingga akan dapat digunakan untuk mengairi sawah (irigasi). Berdasakan sifat dari konstruksinya, Bendung dibedakan atas 2 (dua) tipe bendung sederhana (tidak permanen) dan bendung permanen (Teknis).Bendung Tetap (fix weir), Merupakan jenis bendung yang elevasi mercunya tetap, sehingga elevasi muka air tidak bisa diatur.

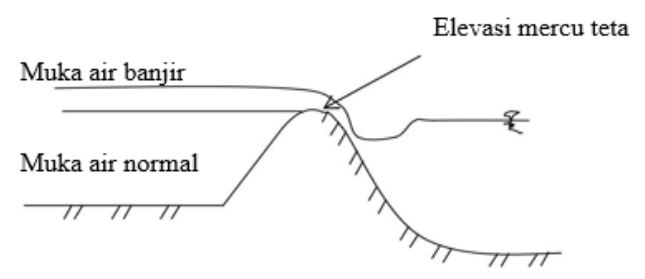

\section{Gambar 1. Elevasi Mercu}

Bendung Gerak (Barrage), merupakan bendung dengan elevasi mercu yang tidak tetap (bisa digerakkan), atau dilengkapi dengan alat pengatur / pintu, sehingga dapat mengatur elevasi muka air. Type Bendung Gerak berdasarkan bentuk alat pengaturnya:

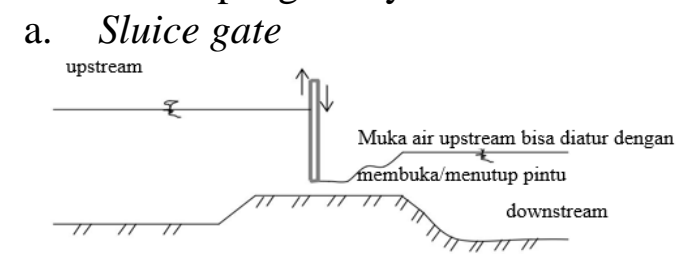

Gambar 2. Bendung Slide Gate

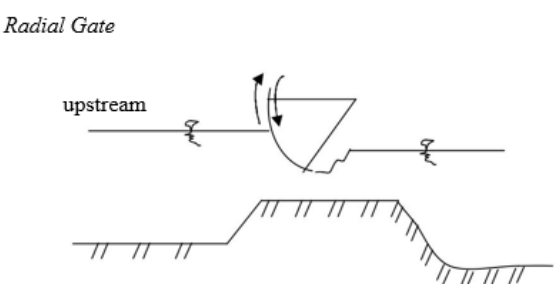

Gambar 3. Bendung Gerak : Radial Gate

c.Bendung Karet

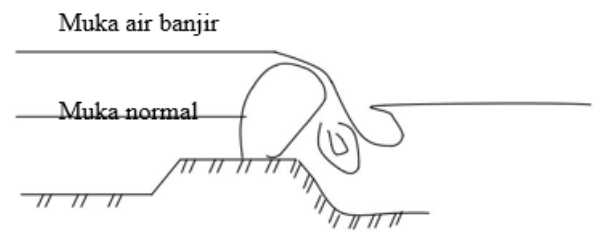

\section{Gambar 4. Bendung Gerak : DAM} bendung Karet

Alat pengatur dari Bendung Karet, dapat dikembang kempiskan sesuai kebutuhan, yaitu dengan menambah atau mengurangi isinya. Isi Bendung karet bisa dari air atau udara.

Analisa debit banjir rencana pemilihan banjir rencana untuk bangunan air adalah suatu masalah yang sangat bergantung pada analisis statistik dari urutan kejadian banjir baik berupa debit air di sungai maupun hujan.

\section{METODE PENELITIAN}

Tempat dan Waktu Penelitian

Untuk tempat penelitian di Pantai utara Jawa Tengah dan mengaplikasikan model di Laboratorium Teknik Sipil Universitas Islam Sultan Agung (UNISSULA) SEMARANG dengan waktu empat bulan. 


\section{Bagan Alir Penelitian}

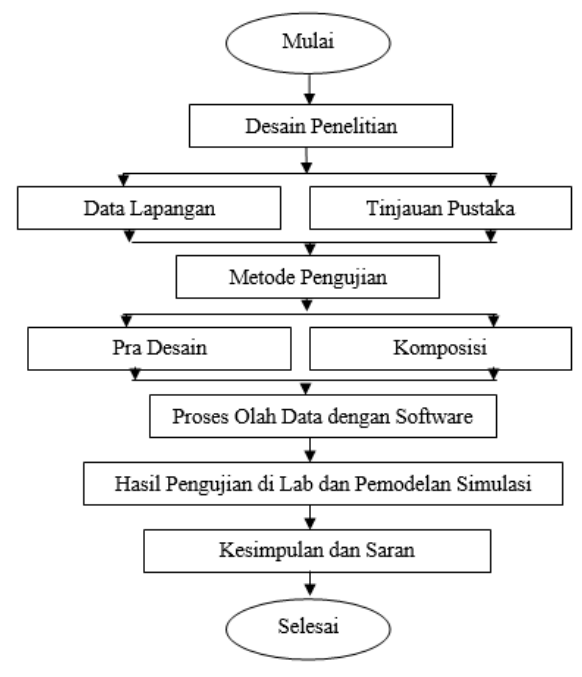

Gambar 5. Bagan Alir Penelitian

\section{HASIL DAN PEMBAHASAN}

Lebar bendung adalah jarak antara pangkal-pangkalnya (abutment) dan sebaiknya sama dengan lebar rata-rata sungai pada bagian yang stabil. Pada bagian ruas bawah sungai, lebar ratarata tersebut dapat diambil pada debit penuh (bankfull discharge), sedangkan pada bagian atas sungai sulit untuk menentukan debit penuh. Lebar maksimum bendung sebaiknya tidak lebih dari 1,2 kali rata-rata lebar sungai pada alur yang stabil.

\section{Tipe Mercu Bendung}

Untuk tipe mercu bendung di Indonesia pada umumnya digunakan dua tipe mercu, yaitu tipe Ogee dan tipe bulat.

Bendung dengan mercu bulat memiliki harga koefisien debit yang jauh lebih tinggi dibandingkan dengan koefisien bendung ambang lebar. koefisien debit menjadi lebih tinggi karena lengkung streamline dan tekanan negatif ada mercu.

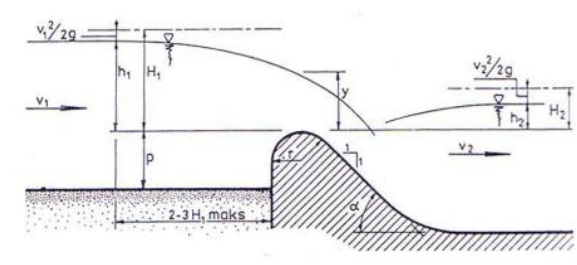

\section{Gambar 6. Bendung dengan Mercu Bulat}

Bagian-Bagian Bendung terdiri dari beberapa komponen Badan Bendung (Body of Dams) berfungsi sebagai penghalang air. Pondasi (Foundation) berfungsi untuk menjaga kokohnya bendung. Pintu Air (Gates) digunakan untuk mengatur, membuka dan menutup aliran air. Daun Pintu (Gate Leaf) yang menahan tekanan air dan dapat digerakan untuk membuka, mengatur, dan menutup aliran air. Rangka Pengatur Arah Gerakan (Guide Frame) menjaga agar gerakan dari daun pintu sesuai dengan yang direncanakan. Angker (Anchorage) untuk menahan rangka pengatur arah gerakan agar dapat memindahkan muatan dari pintu air ke dalam konstruksi beton. Hoist Alat untuk menggerakan daun pintu air agar dapat dibuka dan ditutup dengan mudah. Bangunan Pelimpah (Spill Way) untuk mengalirkan air banjir yang masuk ke dalam waduk agar tidak membahayakan keamanan bendungan.

Bendung karet berfungsi meninggikan muka air dengan cara menggembungkan tubuh bendung dan menurunkan muka air dengan cara mengempiskannya. Pembukaan bendung bisa dilakukan secara otomatis dengan pengempisan tabung karet tersebut, sedangkan pengembangannya hanya bisa dilakukan secara manual. Bendung karet pertama kali dibangun tahun 1957 di Amerika Serikat dengan menggunakan bahan tekstil untuk membentuk tubuh bendung. Pada tahun 
1978 bahan tersebut dikembangkan menjadi serabut nilon yang dibungkus dengan karet sintetis. Pembangunan bendung karet di Indonesia dimulai tahun 1990. Pada penerapannya di lapangan banyak dijumpai berbagai masalah yang berakibat rendahnya kinerja bendung. Masalah tersebut diakibatkan oleh kurangnya dukungan teori dan pengalaman. Selain itu, belum ada pedoman yang bisa dipakai sebagai acuan untuk perencanaan bendung karet. Oleh karena itu, disusun pedoman perencanaan bendung karet. Pedoman ini memuat garis besar tentang dasar pertimbangan untuk membangun bendung karet, persyaratan lokasinya, struktur bendung karet, dan perencanaan teknis.

Macam-Macam Bendung Karet didalam pembuatannya, terdapat 2 macam bendung karet, Bendung Karet Isi Udara, menggunakan udara sebagai media pengisi tabung karet. dan Bendung Karet Isi Air, menggunakan media air sebagai media pengisi tabung karet.

Pemilihan bendung karet harus mempertimbangkan Alternatif penerapan bendung jenis lain yang lebih murah tanpa mengabaikan efektifitasnya bagi tujuan dibangunnya bendung. Bendung karet hanya diterapkan pada kondisi yang apabila digunakan bendung tetap akan menimbulkan peningkatan ancaman banjir yang sulit diatasi. Alternatif bendung karet dipilih apabila bendung gerak jenis lain tidak bisa menjamin kepastian pembukaan bendung pada saat banjir dan rob datang, mengingat daerah yang harus diamankan terhadap ancaman banjir merupakan kawasan Penting.

Persyaratan Pembangunan Bendung Karet Kondisi Alur Sungai; Memiliki aliran subkritik; Tidak terjadi sedimentasi yang sedemikian berat sehingga mengganggu mekanisme kembang-kempisnya tabung karet; Tidak mengangkut sedimen kasar; Aliran sungai tidak mengangkut sampah yang besar dan keras; Air sungai tidak mengandung limbah kimia yang bisa bereaksi dengan karet; Bahan yang digunakan untuk bendungnya sendiri; Media pengisi bendung yang terbuat dari bahan yang elastis, kuat, kedap udara, tidak mudah terabrasi, dan tahan lama; Perencanaan bahan karet baik jenis, kekuatan maupun dimensi hendaknya disesuaikan dengan kemampuan produsen untuk menyediakannya;

\section{Perencanaan Tubuh Bendung}

Lembaran karet terbuat dari bahan karet asli atau sintetik yang elastik, kuat, keras, dan tahan lama. Pada umumnya bahan karet yang digunakan memiliki spesifikasi Kekerasan tes abrasi menggunakan metode H18 dengan beban $1 \mathrm{~kg}$ pada putaran 1000 kali tidak melampaui $0,8 \mathrm{~m} 3 / \mathrm{mil}$. Kuat tarik pada suhu normal $\geq 150 \mathrm{~kg} / \mathrm{cm} 2$

Kuat tarik pada suhu $100 \mathrm{o} \geq 120$ $\mathrm{kg} / \mathrm{cm} 2$. Bahan karet diperkuat dengan susunan benang nilon yang memberikan kekuatan tarik sesuai dengan yang dibutuhkan untuk menahan gaya seperti diuraikan pada butir Bahan dasar karet umumnya digunakan karet sintetis seperti ethylene propylene diene monomer (EPDM), chloroprene rubber (CR), dan lain-lain. Untuk mengurangi goresan oleh benda tajam/keras, permukaan luar karet bisa dilapisi dengan bahan keramik. Kekuatan lembaran karet harus mampu menahan gaya tekanan air dikombinasikan dengan gaya tekanan udara dari dalam tubuh bendung. 
Perencanaan bendung karet didasarkan pada ketentuan secara hidraulik bendung karet harus memenuhi mampu melayani taraf muka air yang direncanakan. Membuka secara otomatis jika terjadi banjir yang melampaui batas tertentu. Pada bendung yang berfungsi untuk menahan intrusi air asin, air asin yang terperangkap di hulu bendung harus bisa didorong ke hilir. Aman terhadap gerusan dasar sungai akibat energi terjunan air. Aman terhadap gangguan akibat arus air dan benda padat yang terangkut. Tinggi bendung karet umumnya tidak melebihi $5,00 \mathrm{~m}$, dengan pertimbangan bahwa konstruksi bendung karet dengan tinggi $>5,00 \mathrm{~m}$ tidak efisien lagi. Secara Struktural Bendung Karet Harus Memenuhi Persyaratan sebagai berikut: Kuat dan stabil terhadap penggulingan penggeseran dan batas daya dukung tanah serta erosi dasar pondasi; Tata letak bendung direncanakan sedemikian rupa sehingga dapat memberikan fasilitas bagi pekerjaan perbaikan tubuh bendung dengan mudah dan murah. Tata Letak Bendung Panjang bentang bendung diusahakan sama dengan lebar normal alur sungai.

Perencanaan instalasi lubang air merupakan lubang bagi pemasukan dan pengeluaran air pada tabung karet. Pompa dan saluran udara harus disediakan untuk mengembangkan tabung karet. Pemopaan udara ke dalam tabung karet harus dilengkapi dengan instrument pengontrol tekanan udara (manometer).

\section{Kriteria Bendung yang Baik}

Dalam kaitannya dengan operasi dan pemeliharaan, bendung karet yang baik mempunyai kriteria bisa dikembangkan dengan baik tanpa mengalami kebocoran. Bisa mengempis secara otomatis danb manual pada kondisi yang direncanakan. Tersedia landasan yang bisa dilakukan dewatering mudah penambalan karet. Tubuh bendung terlindungi dari sengatan sinar matahari, misalnya dengan jembatan penyeberangan. Tubuh bendung aman terhadap gangguan publik dan transportasi sungai. Tubuh bendung tahan terhadap abrasi sedimen aman terhadap arus air dan angkutan sedimen/sampah.

\section{Sistem Otomatisasi}

Prinsip kerja sistem otomatisasi adalah apabila muka air sungai di hulu bendung sudah mencapai muka air pengempisan yang direncanakan, akan terjadi aliran masuk ke dalam sistem, yang diatur untuk menggerakan tuas pembuka tutup saluran udara dari tabung karet. Sistem penggerak tuas yang biasa digunakan sistem ember aliran air ditampung dalam suatu ember yang diikatkan pada kotak otomatisasi. Dengan makin besar berat ember, posisi ember akan turun hingga memutar tuas pembuka tutup saluran udara. Sistem pengapungan aliran air ditampung dalam suatu bak yang di dalamnya dipasang pelampung. Pelampung diikat dengan tali yang dihubungkan dengan kotak otomatisasi. Jika muka air naik, pelampung ikut naik dan menggerakkan tuas pembuka tutup.

Pekerjaan pemeliharaan terdiri atas pemeriksaan secara periodik untuk mengetahui kondisi bangunan. Perawatan secara periodik terhadap masing-masing komponen bendung. Perbaikan yang dilakukan apabila terjadi kerusakan bendung. Pengamanan menerus untuk mencegah kerusakan bendung 
Dampak Positif Pembangunan Bendung Karet untuk Penyediaan air baku daerah pedesaan. Pencegah intrusi air laut. Pengendalian banjir dan penyediaan air irigasi

Dampak Negatif Pembangunan Bendung Karet Pembangunan bendung yang melintang di sungai jika ditinjau dari segi restorasi sungai mempunyai dampak negatif bagi kehidupan biotik dan abiotik di sungai. Beberapa dampak tersebut Mengubah Keseimbangan Angkutan Sedimen. Merubah Elevasi Muka Air Tanah. Pengurangan Debit Air Pada Sungai Utama

\section{KESIMPULAN DAN SARAN Kesimpulan}

Setelah dilakukan analisis terhadap efektivitas pengelolaan bendung karet berisi air untuk pertanian dan penanggulangan banjir dan rob di Pantai utara Jawa Tengah, maka dapat ditarik beberapa kesimpulan :

1. Pemilihan jenis bahan / material yang digunakan pada suatu proyek bendung karet berisi air tergantung dari tekanan stabilitas aliran yang akan melewatinya dan faktor kemudahan sumber bahan / material yang mudah pengopersionalannya.

2. Untuk karakteristik bendung karet isi air sehingga didapatkan material bendung yang baik berdasarkan teknologi tepat guna di dalam negeri belum mudah untuk didapatkannya dalam pasaran bebas.

3. Dalam upaya menanggulangi permasalahan pengairan di musim kemarau pembuatan bendung karet memang perlu dicanangkan. Karena teknologi tepat guna ini dapat menyimpan persediaan air ketika musim penghujan. Dan kepada masyarakat agar turut serta membantu menjaga bendungan yang telah dibuat. Namun ada baiknya kita juga memperhatikan dampak negatif dari pembuatannya.

\section{Saran}

Dari semua tahapan analisis yang telah dilakukan, beberapa saran yang dapat diberikan untuk memperoleh hasil yang lebih baik Pembuatan bendung karet isi air harus dilakukan lebih baik lagi agar tepat guna, dan sebaiknya membuat penelitian kembali tentang metode ini agar bisa membuat bendungan tanpa banyak merusak ekosistem daerah sekitar sungai. Setiap pilihan memang ada resikonya, tapi kita harus berusaha memperkecil resiko tersebut agar keseimbangan tetap terjaga.

\section{DAFTAR PUSTAKA}

1. Badan Pusat Statistik Propinsi Jawa Tengah,2010. Demak Dalam Angka 2010, Demak. Badan Pusat Statistik Propinsi Jawa Tengah,2010. Grobogan Dalam Angka 2010, Grobogan. Dinas Cipta Karya dan Tata Ruang Provinsi Jawa Tengah,2011.

2. Harga Satuan Pekerjaan Bahan dan Upah Pekerjaan Konstruksi Provinsi Jawa Tengah.Semarang. Direktorat Jenderal Pengairan, 1986.

3. Standar Perencanaan Irigasi, Kriteria Perencanaan Bangunan Utama KP-02.Badan Penerbit Pekerjaan Umum. Jakarta. Direktorat Jenderal Sumber Daya Air,2005.

4. Laporan Akhir Studi Optimasi Air Baku Bendung Gerak dan Karet Jajar. PT. Anugerah Krida Pradana. Semarang. Dirjen Pengairan Proyek 
Pengembangan

WS

Jratunseluna, 1999.

5. Dokumen Pelelangan

Pembangunan Tanggul Kali Jajar

Beserta Pintu Klep. Departemen

Pekerjaan Umum. Semarang.

Dirjen Pengairan Proyek

Pengembangan WS

Jratunseluna,1994. Bendung Karet

Isi Udara Kali Jajar. Departemen

Pekerjaan Umum. Semarang.

Kodoatie, R.J dan Sugiyanto,2002.

6. Banjir: Beberapa Penyebab dan Metode Pengendalian Banjir dalam Perspektif Lingkungan. Pustaka Pelajar. Yogyakarta. Laboratorium Jurusan Sipil UNDIP,1992.

7. Hasil Penyelidikan Tanah Pada Lokasi Bendung Jajar Demak. Semarang. Santosa, Kadar,1994. Laporan Kerja Praktek Proyek Bendung Karet Kali Jajar. Fakultas Teknik Jurusan Sipil Universitas 17 Agustus 1945 Semarang. Soemarto, CD, 1999 .

8. Hidrologi teknik. Edisi Dua. Jakarta: Erlangga. Soewarno,1995.

9. Hidrologi Aplikasi Metode Statistik Untuk Analisa Data Jilid Satu. Penerbit Nova. Bandung. Daftar Pustaka Laporan Tugas Akhir Pengendalian Banjir Sungai Jajar Pantai utara Jawa Tengah 258 Sri Harto, Br. Hidrologi Terapan. UGM: Yogyakarta. Triatmodjo, Bambang,2003.

10. Hidraulika II. Beta Offset. Yogyakarta. Unit Produksi dan Jasa Jurusan Teknik Sipil,2005.
Penyelidikan Tanah Cone Penetrometer. Politeknik Negeri Semarang.

11. Soldani F, Foley J. An assessment of rubber dam usage amongst specialists in paediatric dentistry practising within the UK. Int $\mathrm{J}$ Paediatr Dent 2007;17(1):50-56.

12. Marshall K, Page J. The use of rubber dam in the UK: a survey. $\mathrm{Br}$ Dent J 1990;169(9):286-291.

13. Hill EE, Rubel BS. Do dental educators need to improve their approach to teaching rubber dam use? J Dent Educ 2008;72(10): 1177-1181.

14. Whitworth JM, Seccombe GV, Shoker K, Steele JG. Use of rubber dam and irrigant selection in UK general dental practice. Int Endod J 2000;33(5):435-441.

15. Jenkins SM, Hayes SJ, Dummer PM. A study of endodontic treatment carried out in dental practice within the UK. Int Endod J 2001;34(1):16-22.

16. Palmer NO, Ahmed M, Grieveson B. An investigation of current endodontic practice and training needs in primary care in the north west of England. $\mathrm{Br}$ Dent $\mathrm{J}$ 2009;206(11):E22. doi:10.1038/sj.bdj. 2009.1135.

17. Hommez GM, Braem M, De Moor RJ. Root canal treatment performed by Flemish dentists, part 1: cleaning and shaping. Int Endod $\mathbf{J}$ 2003;36(3):166-173. 